\title{
The relationship between ego integrity and death attitudes in older adults
}

\author{
Daniel W. Parker \\ Ave Maria University, San Marcos, Carazo, Nicaragua
}

Email address:

danielparkerphd@gmail.com (D. W. Parker)

\section{To cite this article:}

Daniel W. Parker. The Relationship Between Ego Integrity and Death Attitudes in Older Adults, American Journal of Applied Psychology. Vol. 2, No. 1, 2013, pp. 7-15. doi: 10.11648/j.ajap.20130201.12

\begin{abstract}
This study investigates how one's ability to accept the past contributes to death attitudes within the elderly population. 115 individuals ( 47 men and 68 women) participated by filling out self-report questionnaire packets collected from a variety of residential settings. The Death Attitudes Profile - Revised (DAP-R) was used to assess the individuals attitude towards death and the Ability to Accept the Past scale (ACPAST) was used as a measure of ego integrity. A linear regression analysis was used to determine the predictive relationship between the two variables. The results indicate that scores on the ACPAST are significant predictors of DAP-R subscales Neutral Acceptance Fear of Death and Death Avoidance. The results did not show a significant relationship between the scores on the ACPAST and the DAP-R subscales Approach Acceptance or Escape Acceptance. Thus, the ability to accept the past was a significant predictor of Fear of Death, Death Avoidance, and Neutral Acceptance. Yet, accepting the past was not a significant predictor of Approach Acceptance or Escape Acceptance.
\end{abstract}

Keywords: Death Attitudes, Psychotherapy, Geropsychology, Ego Integrity

\section{Introduction}

The existential realities of human existence take on unique importance in old age. The physical decline of the body, the increased awareness of limitations, major lifetransitions, and the continual experience of losses all require the aging individual to confront with higher frequency, the transitory nature of life. Insufficiently dealing with these issues by denial, suppression, or the inability to accept them, frequently causes suffering in the forms of depression, anxiety, illness, and suicide (Fortner \& Neimeyer, 1999; Langle, 2001). Empirically validating theories and developing interventions that address the existential challenges associated with old age is a much-needed and worthwhile endeavor. In addition, it is important to alter the current notion of aging from one of a negative experience of loss and decline, to a positive experience of gain and growth. The process of aging may facilitate many healthy psychological developments; personal growth, an increased focus on inner reflections, and greater investment of time and focus in relationships. Moreover, Erikson (1982) listed wisdom, integrity, and generativity as some of the benefits of aging. One purpose of this study is to contribute to this positive conceptualization of aging by exploring the predictive factors that may contribute to an accepting attitude toward death.

The relationship between a person's attitude towards death is significantly related to their attitude toward life (Wong, 2000). If a person looks upon his or her life as having been meaningful and fulfilling, despite the hardships and failures, then he will be able to face the reality of his death without excessive fear and anxiety. However, if a person cannot find meaning in his lived experience and is unable to accept the failures and regrets in life, death will be feared, and the overwhelming feeling that one has led an unlived life may lead to depression and despair (Erikson, 1982). In old age, the limitations of one's possibilities and lifespan become especially salient. It can be argued that this increase in awareness further necessitates the development of a healthy attitude toward impending mortality. According to Wong (2008), when we truly accept our death, “....we declare our intention to invest our energy and time in living the good life rather than defending ourselves against the 
inevitable death." He then states that by taking an accepting attitude toward death, it relieves us of anxiety and fills us with energy, "to live with vitality and purpose." He concludes by stating, "“...death acceptance is one of the cornerstones of the good life" (p. 3).

Theory suggests a strong relationship between death attitudes, fulfillment in life, and the ability to accept one's past as meaningful. Moreover, research findings, although relatively few, have shown evidence in support of these theories. Yet, to the best of my knowledge, how one's ability to accept the past contributes to death acceptance within the elderly population has not been investigated. The current study predicts that the greater the ability to accept one's past life experiences as purposeful and worthwhile will result in a more accepting attitude towards impending death.

It is the aim of the current investigation to further clarify the multi-dimensional constructs of death attitudes and ego-integrity as experienced by the older adult. Results from this study and others like it may contribute to a fuller understanding of the existential issues involved in the aging process, ultimately providing therapeutic relief for those who may be suffering.

\section{Death Attitudes and Aging}

As humans we are all aware of our ultimate destiny to die! The awareness of this reality produces anxiety, and this ontological anxiety from which all mankind suffers must be dealt with on a psychological level. Because all human beings must find a way to cope with the terror of death and overcome death anxiety, it is essential to investigate how these different conscious and unconscious strategies affect the quality of life. According to Goodman (1981), "The existential fear of death, the fear of not existing, is the hardest to conquer. Most defensive structures, such as the denial of reality, rationalization, and insulation erected to ward off religiously conditioned separation-abandonment fears, do not lend themselves readily as protective barriers against the existential fear of death" (p.5). How we cope with the awareness of death may have a profound effect on how we live our lives, both positively and negatively. Since the rise of existentialism, the concept of death has been a fundamental element in philosophical and psychological theories that attempt to understand the human experience of life. Philosophical systems have conceptualized the awareness of death as both (a) a threat of non-existence and a key to a richer understanding of life (Heidegger, 1927/1962), and (b) preventing individuals from fully realizing life's possibilities (Sartre, 1943/1966). Both these views point to the potential within death-awareness to powerfully enhance or diminish the human experience of life.

The terror of death has fueled the thoughts of mankind since the beginning of conscious existence. Death represents the unknown and uncontrollable; we all know it will happen to each one of us, yet when and how remain a mystery. However, the awareness of death brings with it positive effects as well. Without temporality and uncertainty, much of what is cherished and considered beautiful would lose its preciousness. The fact that this life will end and that each breath takes us closer to death, brings about a sense of urgency and appreciation. "The act of death may destroy us, but the idea of death may save us"(Yalom, 1980). Further, "the existence of death can bring meaning to life" (Frankl, 1973). Since death awareness is a universal fact containing the potential to enhance life or destroy it, it follows that finding ways to cultivate and promote the positive aspects of death acceptance should be a vital part of every attempt to minister to the human spirit, whether from therapists, religious leaders or caretakers of the sick and elderly.

In today's busy world, filled with distractions and immediate gratifications, it is easy to shrug off the awareness of death, to remove it from our conscious mind, and even to deny its existence by assuming it will happen at some later time in life when one is old and done living. Yet when that "later time" is now and the denial of death is no longer an easy defense, one is stuck with only her attitude toward this reality. Theorists concerned with the psychology of aging have considered awareness of death, its increasing certainty, and its temporal nearness as central to their formulations (Butler, 1963; Cumming \& Henry, 1961; Erikson, 1982). It is for this reason that research must continue to explore the complex relationships of death attitudes among the elderly population.

\subsection{Empirical Findings on Death Attitudes and Older Adults}

Research on death attitudes in older adults is fairly limited. However as increased attention is being given to this area, findings have been somewhat surprising. Contrary to what many have assumed, evidence shows that fear and anxiety about one's own death may actually decrease with age (Gesser, Wong, \& Reker, 1987, 1988; Neimeyer, 1985; Robinson \& Wood, 1984; Stevens, Cooper, \& Thomas, 1980; Thorson \& Powell, 1989). Other well-designed studies have shown that death-related anxiety has a curvilinear pattern with decreased levels in the young and old, but increased levels in middle-aged adults (Bengtson, Cuellar, \& Ragan, 1977; Kalish, 1977). Moreover, studies evidence that older adults express different concerns about death and the dying process than do younger adults. College-age adults typically report concerns regarding annihilation, the afterlife, and how their death may impact the lives of others. Older adults report thinking about death more often than younger adults but are more concerned about issues of dignity, self-sufficiency, and a sense of losing control (Cicirelli, 1997; Thorson \& Powell, 1994). Although these results indicate that overall death-related anxiety may be lower in the elderly than previously thought, findings in a recent meta-analysis of all published articles have yielded several interesting insights. Older adults who reported more physical health problems, a history of psychological distress, weaker religious beliefs, and who scored lower in levels of 
"ego integrity" had heightened levels of death anxiety (Fortner \& Neimeyer, 1999). Another variable of interest is place of residence; those individuals living in assisted living environments showed heightened amounts of death fear compared to those who lived independently.

Therefore, since fearful and anxious attitudes toward death in the elderly do not point to a linear pattern of prediction, the study of attitudes toward death and the psychological aging process becomes especially relevant for inquiry. Clearly, there is importance for understanding the qualities that differentiate those elderly individuals who take an accepting and adaptive attitude toward death versus those who suffer from excessive fear and anxiety.

When studying the aging adult, the psychosocial development of the individual should be taken into account. According to Erikson's (1963) developmental model, the eighth and final stage of adult development is a negotiation concerning acceptance of one's life as having been worthwhile and meaningful. This acceptance also requires reconciliation between the individual's actual self and his/her ideal self. Successful completion of this stage results in achieving integrity and allowing the person to face death without fear. The aging person who views his/her life as having been wasted, will in turn view death as a reminder that it is too late to start over and achieve something meaningful in life, resulting in fear and despair. Therefore, according to Erikson, the ability to accept one's life as it has been lived is a major determinant in whether that person fears death or accepts death.

\subsection{Ego Integrity Versus Despair}

Ego Integrity versus Despair is arguably the least studied of all Erikson's psychosocial stages of development (James $\&$ Zarrett, 2005). However, with the growing population of elderly people and the increase in life expectancy, the psychological processes involved in acceptance of one's self, one's life, and one's death takes on a renewed importance. Moreover, it has been estimated that approximately twenty percent of elderly individuals have clinically significant depressive symptoms and six percent have an anxiety disorder (APA, 2004).

Erikson (1963) described the experience of "ego integrity" as feeling a sense of "enduring wholeness," an affectively integrated belief that one's life makes sense and fits together in a meaningful way. A person who has achieved integrity also finds peace in the idea that past memories and experiences are fixed into history and are inalterable. The failure to achieve ego integrity is to feel despair. The extreme manifestations of despair show up as depression, anxiety, fear of death, pessimism, and an inability to accept and find meaning in one's past.

The concept of ego integrity is complex, and the attempts to conceptualize this broad term into a measurable construct can be difficult. Due to the descriptive similarities between integrity achievement and psychological well-being, some researchers have attempted to measure ego integrity by using measurements of psychological well-being as a proxy (Wagner, Lorion, Shipley, 1983). Other researchers have utilized existing measures of death anxiety or life satisfaction in an attempt to measure levels of ego integrity. The problem is that Erikson (1963) did not offer a formal definition of ego integrity; instead, he specified a number of features related to ego integrity. Without a formal definition, researchers have relied upon measures that assess ego integrity in terms of loosely related items such as combining measures of death anxiety, life satisfaction, attitudes towards aging, and locus of control, not only to measure but also to define ego integrity. "Rather than offering a formulation of ego integrity, researchers have essentially paraphrased Erikson's (1963) description" (Santor \& Zuroff, 1994, p.295). Without a formal definition, it is difficult to generate clear, testable hypotheses that differentiate ego integrity from these other psychological constructs (Santor \& Zuroff, 1994). Therefore, researchers would benefit from focusing not on ego integrity as a whole, but on core components of this construct that can be conceptualized and empirically validated as relating to psychological well-being and successful aging.

Santor and Zuroff (1994) Propose “...A core component of ego integrity involves the internal representation of the past as acceptable or satisfactory" (p.296). Accepting the past has been argued by Erikson (1963) to be a fundamental process involved in the psychological development of the older person during the final stage of life. Due to the diversity of the content domain within the construct of ego integrity, Santor and Zuroff, (1994), developed the "Accepting the Past Scale" in an attempt to operationalize a core component of ego integrity. Although Erikson's (1963) description of ego integrity includes other important factors (an absence of death anxiety, tolerance and acceptance of others, and adaptability), focusing on this core component will provide a more manageable construct that can be successfully operationalized and subjected to empirical investigations (Santor \& Zuroff, 1994).

\subsection{Empirical Findings on Accepting the Past}

Santor and Zuroff (1994) defined "accepting the past" as an ongoing process involving the internalization and integration of past experiences into a general representation of the past. Individuals who accept the past as satisfying experience positive feelings and give positive evaluations about the past without experiencing excessive negative feelings or disappointment. Individuals who fail to accept the past view their life as disappointing or meaningless and may experience a deficit in self-worth or a negative self-concept (p. 297). Lacking feelings of self-worth has been linked to depression (Beck, 1967; Ruble, Constanzo, \& Higgins, 1992). Therefore, it can be hypothesized that a failure to accept the past may result in feelings of depression. The impact of depression in later life can be especially severe; potentially compromising the daily functioning of life and if untreated may contribute to premature death (Ames, Ashby, Mann, \& Graham, 1988). There have been relatively few studies on the relationship between accepting the 
past and mental health in the elderly.

The relationship between "accepting the past" and Erikson's (1963) construct of ego integrity has been linked by a comparison study using an existing self-report measurement of ego integrity (Ryff \& Heincke, 1983). Using a sample of retired university employees aged 55 and older, Santor and Zuroff (1994) demonstrated a strong relationship between "accepting the past" and an existing self-report measure of ego integrity. In addition, accepting the past was shown to be a better predictor of depression within the sample. However, "accepting the past" was only a predictor of depression in those individuals who also scored high on negative affectivity. These findings suggest that the relationship between depression and accepting the past may be moderated by negative affectivity.

Conversely, Rylands and Rickwood (2001) found a significant relationship between accepting the past and depression that was not contingent upon the presence of high negative affectivity. In their study, seventy-three elderly Australian women residing in a retirement community were studied using the following self-report measures: the Geriatric Depression Scale (GDS); Accepting the Past Scale (ACPAST); the Positive Affectivity and Negative Affectivity Scales (PANAS); the Social Resource Scale (OARS); and the Instrumental Activities of Daily Living Scale (IADL). Rylands and Rickland (2001) concluded their research study stating "....accepting the past was shown to have a direct and substantial effect on mental health in older people" (p.85). However, the study used a relatively small sample of subjects, the participants were all from the same community in Australia, and all were women. Therefore, generalizing these results to populations outside of that geographical area and of a different gender is not possible.

Research findings that suggest the importance of accepting the past in the treatment of the elderly also stem from investigations of life review therapy (Butler, 1963; Fry, 1983; LoGerfo, 1980; Merriam, 1993). The focus of life review therapy is to help the older adult review his/her life story in an attempt to understand and accept negative past experiences (Butler, 1963). The effectiveness of life review therapy as evidenced by Fry (1983\&1991), and LoGerfo (1980), has shown it to be successful in reducing feelings of depression, frustration, low self-esteem, and in promoting a greater feeling of control over one's life.

Therefore, previous research suggests accepting the past not only has a positive relationship with characteristics associated with psychological well-being and ego integrity in the elderly, but it also has therapeutic value. If accepting the past requires a person to negotiate and accept the unchangeable facts of his/her life, can this also be applied to the unchangeable fact of his/her death? One question this study intends to investigate is whether an accepting attitude towards one's past is related to an accepting attitude towards one's death.

\subsection{Accepting the Past and Death Attitudes}

Theory suggests a strong link between ego integrity development and end of life issues. Yet, the research on ego integrity-related constructs such as accepting the past and its relationship with attitudes toward death has been meager. Moreover, the majority of those studies done on death attitudes and ego integrity related constructs use measures of overall psychological well-being, purpose in life, or life satisfaction as a proxy for ego integrity (Fortner \& Neimeyer, 1999). Using such broad psychological constructs to measure ego integrity becomes problematic when trying to tease out and conceptualize cause and effect relationships that can be applicable to therapeutic treatments.

Though the literature findings are sparse, one study (Whalaskay, Whitbourne, \& Nehrke, 1983-1984) reported a negative relationship between death anxiety and ego integrity achievement in older adults as measured by the Inventory of Psychosocial Development and the Death Anxiety Scale. Nevertheless, this study used a measure of ego integrity based upon various characteristics of the construct as described by Erikson (1963). Although this test may be a more precise measurement of integrity than psychological well-being or purpose in life, it still is too broad, measuring a range of psychological phenomena. One argument for this current study is that in order to transfer theories and correlational data into meaningful therapeutic applications, researchers must focus their efforts on teasing out the measurable components of complex constructs.

Accepting the past challenges the older adult to find meaning in all aspects of his/her life; past, present, and future. The ability to find meaning and ultimately accept one's life results in achieving integrity. The inability to accept one's life and the belief that there is not enough time to try out new paths that would facilitate integrity results in existential anxiety and despair. The concept of despair has been described by Frankl (1992) as suffering without meaning. Therefore, in the later stages of life, individuals are motivated to review their lives in an attempt to find meaning. This life review process may facilitate an acceptance of the past, and more importantly, an acceptance of the future, including death. It can be argued that accepting one's life and death brings a sense of peace and assurance that may contribute significantly to the psychological well-being of older adults.

Thus far, the majority of the research examining death attitudes among the elderly has focused on the negative outcomes associated with this realization. However, it is arguably as important to focus on the positive outcomes of aging in order to promote hope, health, fulfillment, and vitality in the aging adult. Langle (2001) conceptualized this positive view of aging quite eloquently when he described it as:

“...a process leading man out of distraction and diversification, wherein he could lose himself, and bringing him back to reflect upon himself and his life. It is a process designed for the concentration of life. Here, man is once again confronted with the basic questions of human existence, with all the hardness and singularity of life, but also with 
the satisfaction of not being able to lose that which has been lived" (p. 215).

Within this description of aging, Langle (2001) points out the importance of acknowledging and accepting one's past experiences as something valuable and meaningful despite the hardships endured. The present study asks the question, "Does the ability to accept and find meaning in one's past experiences contribute to accepting and finding meaning in one's future death?"

\section{Methods}

115 individuals participated in this study, consisting of $41 \%$ men $(n=47)$ and $59 \%$ women $(n=68)$. The mean age for this study sample was 73 years and the age range was from 60-91 years. The data was collected using questionnaire packets that were either handed out by the author of the study in person, or through the mail. Participants were asked to return the packets to the places where they were picked up in person or through the mail using the provided self-addressed stamped envelope. Questionnaire packets were distributed to and collected from a variety of locations in both southern and northern California, including retirement communities, senior citizen housing and apartment complexes, church-related organizations, and community centers. Of the 344 questionnaire packets distributed, 118 (34\%) were returned. Of the 118 returned packets, three were found to have over half the question items not filled out and therefore were not used in this study sample.

\subsection{Instruments}

\subsubsection{The Death Attitude Profile - Revised}

Consisting of 32-items, scored on a Likert scale with responses ranging from "strongly disagree" to "strongly agree," the DAP-R is a multi-dimensional measure of death fear, death avoidance, and death acceptance. Developed by Wong, Reker, \& Gesser (1994), the DAP-Revised version of the original Death Attitude Profile (DAP), which was also developed by Wong and colleagues, was designed to expand the original measure of death attitudes and to further consider the positive dimensions of death acceptance. The DAP-R has five subscales: (a) Fear of Death, (b) Death Avoidance, (c) Neutral Acceptance, (d) Approach Acceptance, and (e) Escape Acceptance. The unique contribution of this measure is the inclusion of attitudes of acceptance toward death. Wong et al (1994), propose that along with a positive acceptance toward death, approach acceptance (a belief in some type of afterlife and that physical death is the gateway to that afterlife), or neutral acceptance (a belief that death is just a natural and inevitable part of life that need not be feared), one can also look to death as an opportunity to escape the physical or psychological suffering in this life; escape acceptance. Research has found that neutral acceptance and approach acceptance are related to psychological and subjective well-being, respectively. However, escape acceptance is related to lower physical well-being (Wong et al., 1994).
According to Wong, et al. (1994), results from a principal factor analysis yielded a five-factor analysis, which accounted for $66.2 \%$ of the variance, with the items on the five factors corresponding to the expected dimensions of death attitudes (Reimer, 2007). However, a later study investigating the psychometric properties of the DAP-R reported the items loading on six factors, showing the Neutral Acceptance dimension loading on two different factors (Clements \& Rooda, 1999-2000). Results from this study, as well as the lowered level of internal consistency for the Neutral Acceptance subscale suggest that it may be measuring more than one construct. However, despite its limitations, this subscale will still be used in the current study. Theoretically, Neutral Acceptance displays a healthy integration of death into a person's life, which is related to a successful negotiation of Erikson's (1950) eighth stage of psychosocial development. Therefore, it can be argued to be a worthwhile inclusion for the current study.

\subsubsection{The Accepting the Past Scale}

Santor \& Zuroff (1994) designed the Accepting the Past Scale (ACPAST) to measure the core component of Erikson's (1963) concept of ego integrity. Consisting of 16 self-report items scored on a 7-point Likert scale, the respondent rates the degree to which each statement resonates with their personal experience. Each item can be rated on a scale ranging from "strongly agree" to "strongly disagree," with the middle range designated as a "not certain/don't know" response. Examples of items include, "Sometimes I have the feeling that I've never had the chance to live"; "Generally, I feel contented with the way my life has turned out"; and "Some personal experiences from earlier on are still too difficult to think about." Scoring the ACPAST consists of summing the total of all items, giving a possible range between 16 and 112, with the higher the score indicating the greater the difficulty in accepting the past.

An investigation of the psychometric properties suggests the ACPAST is both a valid and reliable measure. Santor \& Zuroff (1994) report an internal reliability coefficient, as determined by Cronbach's alpha level, for all items to be .86 . Convergent validity of the ACPAST with existing measures of ego integrity has also been shown to be good. Moreover, content validity coefficients for each item-total correlation are reported to range from .26 to .69 at a (p $<$.001) significance level (Santor \& Zuroff, 1994).

Internal consistency coefficients were calculated for both measures. The DAP-R coefficients for each subscale ranged from .42 (Neutral Acceptance) to .96 (Approach Acceptance), though not uniformly high, these scores demonstrate an adequate level of internal consistency. The ACPAST yielded a $\alpha$ coefficient of .90 , which is considered to be a relatively high score of internal consistency.

\section{Results}

Regarding death attitudes, individuals in this sample scored lower on both the fear and death avoidance scales 
and highest on neutral acceptance. Scores on the ACPAST indicate that individuals within this sample, tended to have greater degrees of accepting the past and less regret about past events and experiences. The first hypothesis for this study predicts that there will be a significant negative correlation between the scores on the ACPAST and the DAP-R subscales: Neutral Acceptance and Approach Acceptance. Thus, one's ability to accept the past as worthwhile and meaningful will be a predictor of a more positive and accepting attitude toward death.

Table 1. A survey of study sample $(N=115)$ mean scores, standard deviation, minimum and maximum score possible on each of the variables.

\begin{tabular}{llllll}
\hline Variable & Mean & SD & Min. & Max. & Max.Possible \\
\hline Fear of Death & 17.32 & 7.18 & 7 & 43 & 49 \\
Death Avoidance & 13.70 & 6.55 & 5 & 32 & 35 \\
Neutral Acceptance & 29.42 & 3.55 & 17 & 35 & 35 \\
Approach Acceptance & 54.77 & 15.85 & 12 & 70 & 70 \\
Escape Acceptance & 23.74 & 7.13 & 5 & 35 & 35 \\
ACPAST & 40.55 & 17.73 & 16 & 89 & 112 \\
\hline
\end{tabular}

Linear Regression Analyses were performed to test the current hypothesis. The results indicate that there is a statistically significant predictive relationship between scores of the ACPAST and the DAP-R subscale Neutral Acceptance $\left(\mathrm{R}=-.21, \mathrm{R}^{2}=.043, \mathrm{p}<.05\right)$, suggesting the expected results that the greater amount of acceptance of one's past lived experience is significantly related to having a greater amount of a Neutral Acceptance toward their own death. However, contrary to prediction, results did not show a significant relationship between the scores obtained on the ACPAST and the DAP-R subscale Approach Acceptance $\left(\mathrm{R}=.023, \mathrm{R}^{2}=.00, \mathrm{p}>.05\right)$.

The second hypothesis predicts that there will be a significant predictive relationship between scores obtained on the ACPAST and the DAP-R subscales: Fear of Death and Death Avoidance. Therefore, the inability to accept one's past as worthwhile and meaningful will predict greater endorsement of fearful and/or avoidant attitudes toward death. In the case of Escape Acceptance, it is hypothesized that this inability to accept the realities of one's life will be a predictor of a desire to escape life and will endorse a welcoming attitude towards one's personal death.

As was conducted with each previous analysis, a linear regression analysis was conducted to examine the relationship between ACPAST and Fear of Death, Death Avoidance, and Escape Acceptance independently. The results of the analysis confirmed the hypothesis that scores on the ACPAST are significant predictors of Fear of Death $(R=.402$, $\left.\mathrm{R}^{2}=.162, \mathrm{p}<.001\right)$ and Death Avoidance $(\mathrm{R}=.273$, $\left.\mathrm{R}^{2}=.075, \mathrm{p}<.001\right)$. Thus providing evidence for the prediction that the lesser one's ability to accept their past lived experience as meaningful the greater amount of negative attitudes towards death will be present, in particular, a fear of death and an avoidance of death related thoughts. Regarding Escape Acceptance, results did not show a significant relationship between the scores obtained on the ACPAST and Escape Acceptance $\left(\mathrm{R}=.165, \mathrm{R}^{2}=.03, \mathrm{p}>.05\right)$. Explanations and possible interpretations about these results will be discussed further in the following section.

\section{Discussion}

The human experience of life demands the conscious being to face and deal with the many existential realities inherent within one's world. The process of aging and the unavoidable fact of a personal death are two such existential realities that many human beings have historically struggled to personally accept within one's life. Human Beings are unique in their capacity to be cognitively aware of their own impending mortality, this burden of awareness brings with it existential anxiety and fear not only about what may come after death, but also about the meaning of one's lived life both in the past and in the present. The rising population of older adults since the baby-boomer generation and the high levels of depression and anxiety seen within this population argue for continued research and focus on the psychological, psycho-spiritual, and psycho-social experience that is unique to the older adult. The current study is an attempt to empirically examine some of these existential issues that are inherent within the human condition of life, and seem to be of particular importance during the later stages of this life.

\subsection{Accepting the Past and Death Attitudes}

The results of the statistical analysis showed a significant predictive relationship between the ability to accept the past (ACPAST) and the DAP-R subscale Neutral Acceptance. These results indicate that the greater one's ability to accept their past lived experience in life as being a necessary and meaningful whole despite the failures and regrets, the greater the endorsement of a Neutral Acceptance attitude toward death. This lends support to Erikson's (1963) eighth stage of psychosocial development, "ego integrity." According to Erikson, the psychosocial developmental stage that becomes most prominent in old age is "ego integrity vs. despair." Furthermore, he points out that the attainment of ego integrity requires a lot of thought into the meaning of one's life through the acceptance of a lifelong series of choices (Erikson, 1980). It is plausible that the attitude that is demonstrated through the endorsement of items on the Neutral Acceptance scale also demonstrate the person's ability to face, without denial, the existential realities of life, including not only what is, but also what has been. Therefore, according to the results from this study, the more a person has been able to accept the facts of their life with less regret and despair, the greater the probability they will also accept the fact of their impending death with less fear and anxiety. However, contrary to prediction, there was no 
significant relationship between the ACPAST and Approach Acceptance. One possible explanation of these results is that having a strong faith in God and the afterlife associated with that God, one is still able to come to an accepting attitude towards their mortality that is rooted in the belief of a blissful eternity. It is plausible that one's belief in a rewarding afterlife will override the need to "take care of things" in this world since the focus may be on a future existence and less importance is given to the deeds of the present existence.

Looking at the other side of death attitudes, it was predicted that scores on the ACPAST would have a predictive relationship with the DAP-R subscales Fear of Death, Death Avoidance, and Escape Acceptance. Otherwise stated, the lesser one's ability to accept their past lived experience in life, the greater endorsement of fearful and/or avoidant attitudes toward death, and in the case of Escape Acceptance, a welcoming attitude towards death as the final relief from the misery of life. The results from the analysis suggest that one's ability to find meaning and acceptance of the past reduces the amount of fearful and avoidant attitudes toward death. These findings are also consistent with Erikson's theory of ego integrity: "if we have lived a meaningful life and achieved ego integrity, we are able to face death without fear" (Erikson, 1982). Surprisingly, the results from this study show a lack of a statistically significant relationship between the ACPAST and the DAP-R subscale Escape Acceptance. This result was unexpected because it does not support the common belief that when a person is unable or unwilling to accept the existential realities of his past experience in life, the perceived value of life is lessened and the idea of death may be viewed more as a relief from a burden. However, upon further analysis, many other variables may be influencing the outcome of one's personal analysis of their past life experience and death attitude. It is conceivable that the individual, although deeply bothered by past regrets, failures, and mistakes in life, still harbors hope for change. The person that may be unable to find contentment with what has been written on the pages of their life's story thus far, still endorses a belief that the pages from this day on are blank and the responsibility to author one's own life falls upon oneself. Other factors that may be contributing to the lack of statistical relationship may be physical or emotional discomfort. The physical pain of illness or the emotional suffering from grief and loss may contribute to feelings of wanting to escape a lonely and/or painful existence although they may have lived a full, happy and vibrant life before the loss or the sickness. It would be valuable to investigate qualitatively the personal experience of accepting one's past and how this may influence one's attitude towards their impending mortality. An in depth qualitative study may help to develop a more comprehensive view of the personal faculties involved that are influencing the way people approach these very real existential facts of the human condition.

\subsection{Clinical Implications}

Psychotherapy with an older adult can prove to be a challenging task; the clinician must call upon the personal resources within to step into the world of the aging client. Life presents difficulties for all persons, but for the older adult there are added existential challenges that take center stage. Alfried Langle (2001) states: "To encounter an aging or old person and provide adequate help and emotional support calls for knowledge of the existential reality of old age beyond medical and nursing care. To deal personally with this reality in one's own experience as well as knowing about the specific burdens and problems of aging are prerequisite for entering the world of the old person and offering meaningful support." Many of the issues in the forefront of psychotherapy with older clients are universal in all people's lives regardless of age, however some seem to be a more frequent theme when treating the aging person. One such topic that touches everyone's life, is death. The reality of death is an inescapable part of life that impacts everyone at some point in time. This can be the death of a loved one, the death of a social role, the death of a relationship, or the loss of the self. The experience of losing the self or losing the other is one of the most significant trials a person faces (Mannarino, Eliason and Rubin, 2008). How one responds to this threat varies widely and has significant impact on how one lives their life. It is the task of the aging person to deal with and integrate every aspect of the aging process that is happening to the self. The person is bound to do so because "she is not passively subjected to the processes of aging, as in the case of an animal, but has to experience aging within her own horizon of understanding. She needs to understand the world differently in old age through the age-transformed way of being-in-the-world" (Langle, 2001).

The current investigation sheds light on the important questions regarding the role of ego integration in the management of death related fear and anxiety. Therapeutic techniques such as reminiscence therapy, which focus on reflecting back upon one's life in an attempt to make amends with one's past and integrate the whole of life's experiences into a meaningful context may prove to be of significant therapeutic value for older adults. Moreover, the process of aging can be viewed as a process of concentration, when life is less dependent on superficial distractions and diversification. Langle (2001) writes: "Here, man is once again confronted with the basic questions of human existence, with all the hardness and singularity of life, but also with the satisfaction of not being able to lose that which has been lived." The fact that there is less life ahead and more life behind, suggests that the older adult could benefit from looking to this past lived experience for the personal resources that may help in confronting the fundamental dilemmas of the human condition.

\subsection{Study Limitations and Future Research}

The most obvious limitation of the current study is the lack of diversity among the sample population. The current sample was overwhelmingly Caucasian, and the vast ma- 
jority identified themselves as Christian. It is suggested that future research should attempt to gather data from a population sample that represents a greater diversity in both cultural and religious traditions. Therefore one should take caution when attempting to generalize these findings to an older adult population that does not identify as being either Caucasian or Christian. Another limitation of the current study is relatively small sample size of 115 people. It is believed that a larger sample size would clarify any trends that were seen within the data. Also, the respondents in the current study were largely living independently and in their own residences, future studies may wish to focus on the differences between older adults living independently in the community and those living in hospice programs and assisted living facilities. The relatively low response rate of the mailed questionnaires should also be taken into consideration when analyzing the results. It is possible that individuals that were more comfortable with reflecting upon and answering questions about deep and meaningful existential issues of their life were more likely to respond. Therefore, the study sample may be limited in its representation of individuals that have a more difficult time examining their current views on death, their feelings about their past, and the amount of meaning perceived in life. It is important to keep in mind that the need for multi-dimensional research, not only when choosing and utilizing measurement tools, but also when analyzing variables is essential. It is unlikely that the current analysis that examines the relationship between two variables is able to account for the whole picture of what is being studied. Future researchers should use other recruitment methods that will likely result in a more representative sample of people with varying comfort levels in answering such questions. Lastly, the assessment of death attitudes was conducted through self-report survey questionnaires. People may not be consciously aware of their fear and anxiety of death until they are confronted with the prospect of their own mortality. Thus, it may be easier for a person to report less death fear when one is relatively healthy (Cicirelli, 2002). This points to another reason for future research to make efforts in sampling older adults that reside in nursing home or hospice programs.

With consideration of the above mentioned limitations, the author cautiously concludes that the attainment of ego integrity conceptualized as the ability to accept the past plays an important role in the death attitudes of older adults. In particular, negative death attitudes of fear and avoidance and the existentially oriented attitude of neutral acceptance appear to be the most influenced.

\section{References}

[1] American Psychological Association (2004). What Practitioners Should Know about working with Older Adults. Washington, D.C.

[2] Ames D; Ashby D; Mann AH; Graham N. (Jul 1988). Psy- chiatric illness in elderly residents of Part III homes in one London Borough: prognosis and review. Age Ageing, 17, 249-256.

[3] Beck, A. (1967). Depression. New York: Harper \& Row.

[4] Bengtson,V. L., Cuellar, J. B., \& Ragan, P. K. (1977). Stratum contrasts and similarities in attitudes toward death. Journal of Gerentology, 32, 76-88.

[5] Butler, R.N. (1963). The life review: An interpretation of reminiscence in the aged. Psychiatry, 26, 65-76.

[6] Cicirelli, V. G. (2002). Fear of death in older adults: Predictions from terror management theory. Journal of Gerontology: Psychological Sciences, 57B, P358-P366.

[7] Cicirelli, V.G. (1997). Relationship of psychosocial and background variables to older adults' end of life decisions. Psychology \& Aging, 12, 72-83.

[8] Clements, R., \& Rooda, L.A. (1999-2000). Factor structure, reliability, and validity of the Death Attitude Profile - Revised. Omega: Journal of Death \& Dying. 40, 453-563.

[9] Cumming, E. \& Henry, W.H. (1961). Growing old: The process of disengagement. New York: Basic Books.

[10] Erikson, E. H. (1963). Childhood and society ( $2^{\text {nd }}$ Ed.). New York: W.W.Norton.

[11] Erikson, E. H. (1980). Idenity and the life cycle. New York: W.W. Norton.

[12] Erikson, E. H. (1982). The life cycle completed. New York: W.W. Norton.

[13] Fortner, B.V., \& Neimeyer, R. A. (1999). Death anxiety in older adults: A quantitative review. Death Studies, 23, 387-411.

[14] Frankl, V.E. (1966). Self-transcendence as a human phenomenon. Journal of HumanisticPsychology, 6, 97-106.

[15] Frankl, V.E. (1973). The doctor and the soul: From psychotherapy to logotherapy. Pelican, Harmondsworth.

[16] Frankl, V. E. (1992). Man's search for meaning: An introduction to logotherapy. Boston: Beacon Press (Originally published in 1959).

[17] Fry, P. (1983). Structured and unstructured reminiscence training and depression among the elderly. Clinical Gerontologist, 1 (3), 15-37.

[18] Fry, P. (1991). Individual differences in reminiscing among older adults: Predictors of frequency and pleasantness ratings of reminiscence activity. International Journal of Aging and Human Development, 33, 311-326.

[19] Gesser, G., Wong, P. T. P., \& Reker, G. T. (198771988). Death attitudes across the life-span: The development and validation of the Death Attitude Profile. Omega,18,113-128.

[20] Goodman, L. M. (1981). Death and the creative life: Conversations with eminent artists and scientists as they reflect on life and death. New York: Springer.

[21] Heidegger, M. (1962). Being and time. London: SCM Press LTD. (Original work published 1927).

[22] James, J.B., \& Zarrett, N., (2005). Ego integrity in the lives 
of older women: A follow-up of Mothers from the Sears, Maccoby, and Levin (1951) Patterns of child rearing study. Journal of Adult Development, 12(4), 155-167.

[23] Kalish, R. A. (1977).The role of age in death attitudes. Death Education, 1, 205-230.

[24] Kazdin, A. E. (2003) Research design in clinical psychology. Boston: Allyn \& Bacon.

[25] Langle, A. (2001). Old age from an existential-analytical perspective. Psychological Reports, 89, 211-215.

[26] LoGerfo, M. (1980). Three ways of reminiscence in theory and practice. International Journal of Aging and Human Development, 12, 39-48.

[27] Mannarino, M.B., Eliason, G., and Rubin, J. (2008). Regret therapy: Coping with death and end of life issues. In Tomer, A., Eliason, G., \& Wong, P.T.P., Existential and spiritual issues in death attitudes. New York: Taylor \& Francis.

[28] Merriam, S. (1993). Butler's life review: How universal is it? International Journal of Aging and Human Development, 37 (3), 163-175.

[29] Neimeyer, R. A. (1985). Actualization, integration and fear of death: A test of the additive model. Death Studies, 9, 235-250.

[30] Neimeyer, R.A. \& Fortner, B. (1997). Death attitudes in contemporary perspective. In Strack, S. (Ed.) Death and the quest for meaning: Essays in honor of Herman.

[31] Feifel_(pp. 3-29). Northvale, NJ: Jason Avonson.

[32] Neimeyer, R. A., Wittkowski, J. \& Moser, R., (2004). Psychological research on death attitudes: An overview and evaluation. Death Studies, 28: 309-340, 2004.

[33] Reimer, S.E. (2007). A test of a model of positive and negative death attitudes among family caregivers of the elderly. Unpublished doctoral dissertation. Ohio State University, Ohio.

[34] Robinson, P. J., \&Wood, K. (1984). Fear of death and physical illness. In F. Epting \& R. A. Neimeyer (Eds.), Personal meanings of death (pp. 127-142).Washington, DC: Hemisphere.

[35] Ruble, D. N., Costanzo, P. R., \& Higgins, E. T. (1992). Social psychological foundations of mental health. In D. N. Ruble, P. R. Costanzo, \& M. Oliveri (Eds.), The social psychology of mental health: Basic mechanisms and applications. New York, NY: The Guilford Press.

[36] Ryff, C., \& Heincke, S.G. (1983). Subjective organization of personality in adulthood and aging. Journal of Personality and Social Psychology, 69, 719-727.

[37] Rylands, K.J., \& Rickwood, D.J. (2001). Ego-integrity vs. ego-despair: The effect of "accepting the past" on depression in older women. International Journal of Aging and Human Development. 53 (1), 75-89.
[38] Santor, D.A., \& Zuroff, D.C., (1994). Depressive symptoms: Effects of negative affectivity and accepting the past. Journal of Personality Assessment, 63(2), 294-312.

[39] Sartre, J.P., 1966. Being and nothingness: An essay on phenomenological ontology. New York: Citadel Press. (original work published 1943).

[40] Stevens, S. J., Cooper, P. E., \& Thomas, L. E. (1980). Age norms for Templer's Death Anxiety Scale. Psychological Reports, 46, 205-206.

[41] Thorson, J. A., \& Powell, F. C. (1994). A revised death anxiety scale. In R.A. Neimeyer (Ed.), Death anxiety handbook: Research, instrumentation, and application. Philadelphia: Taylor \& Francis.

[42] Thorson, J. A., \& Powell, F. C. (1989). Death anxiety and religion in an older male sample. Psychological Reports, 64, 985-986.

[43] Tomer, A., \& Eliason, G., (2008). Regret and death attitudes. In Tomer, A., Eliason, G., \& Wong, P.T.P., Existential and spiritual issues in death attitudes. New York: Taylor \& Francis.

[44] U.S. Bureau of the Census (2010). The older population in the United States (P20-564). Washington DC: Bureau of the Census.

[45] Wagner, K.D., Lorion, R.P., and T.E. Shipley. (1983) Insomnia and psychosocial crisis: Two studies of Erikson's developmental theory. Journal of Consulting and Clinical Psychology 51(4), 595-603.

[46] Whalaskay, M., Whitbourne, M.K., \& Nehrke, M.F. (1983-1984). Construction and validation of an ego integrity status interview. International Journal of Aging \& Human Development, 18, 61-62.

[47] Wong, P.T.P. (2008). Meaning management theory and death acceptance. In Tomer, A., Eliason, G., \& Wong, P.T.P., Existential and spiritual issues in death attitudes. New York: Taylor \& Francis.

[48] Wong, P.T.P. (2000). Meaning of life and meaning of death in successful aging. In A. Tomer (Ed.), Death attitudes and the older adult: Theories, concepts and applications (pp. 23-36). Washington, DC: Taylor-Francis.

[49] Wong, P. T.P, Reker, G. T., \& Gesser, G. (1994). Death attitude profile--revised: A multidimensional measure of attitudes toward death. In R. A. Neimeyer (Ed.).

[50] Death anxiety handbook: Research, instrumentation, and application. (pp. 121-148). Philadelphia, PA: Taylor \& Francis.

[51] Yalom, I.D. (1980). Existential psychotherapy. New York. Basic Books. 